\title{
CHORISTOMA OF LIVER - A CASE REPORT
}

\author{
Deepa Longjam ${ }^{1}$, L. Radita Devi², Kh. Sunitarani ${ }^{3}$
}

${ }^{1}$ Tutor, Department of Pathology, J. N. Institute of Medical Sciences, Imphal. ${ }^{2}$ Tutor, Department of Pathology, J. N. Institute of Medical Sciences, Imphal. 3Tutor, Department of Pathology, J. N. Institute of Medical Sciences, Imphal.

\section{ABSTRACT}

\section{BACKGROUND}

Choristoma or Ectopic Liver is a rare condition in which the hepatic tissue is located at a site away from its usual anatomical location. It is incidentally identified during laparotomy or laparoscopy for other disorders. Resection of the ectopic liver en bloc with the gall bladder is the standard treatment.

\section{KEYWORDS}

Heterotopic Liver, Gall Bladder, Laparoscopy.

HOW TO CITE THIS ARTICLE: Longjam D, Devi LR, Sunitarani Kh. Choristoma of liver - A case report. J. Evolution Med. Dent. Sci. 2016;5(91):6798-6799, DOI: 10.14260/jemds/2016/1536

\section{BACKGROUND}

Ectopic liver or Choristoma is a rare condition in which the hepatic tissue is located at a site away from its usual anatomical location. It is also known as heterotopic liver. ${ }^{1}$

The incidence of choristoma liver ranges from $0.24 \%$ to $0.47 \%$ and most of the cases are diagnosed at laparotomy or laparoscopy. Here, we are reporting an unexpected finding of choristoma of liver during laparoscopic cholecystectomy. ${ }^{2}$

\section{CASE REPORT}

A cholecystectomy specimen of a 42-year-old woman was received in our department of pathology. History revealed she had an episode of right upper quadrant abdominal pain, colicky in nature and radiating to right shoulder for the last 3 months. It was also associated with nausea and non-bilious vomiting. For which she consulted a gastro-intestinal surgeon, and she was advised ultrasonography (USG). USG showed multiple gallstones for which she underwent elective laparoscopic cholecystectomy (Figure 1) under general anaesthesia. The postoperative period was uneventful, and she was symptom free at the time of discharge. Gross examination of the cholecystectomy specimen showed a well-defined brownish nodule measuring about $1.5 \mathrm{~cm} \times 1 \mathrm{~cm}$ which is attached to the anterior wall of the gall bladder. The excised gall bladder measured $8 \mathrm{~cm} \times 2 \mathrm{~cm} \times 2 \mathrm{~cm}$ and contained numerous yellowish stones on cut section. Microscopic examination of the resected brownish nodule revealed histologically normal hepatic tissue with portal tract and central vein. The gall bladder showed feature of chronic cholecystitis (Figure 2).

Financial or Other, Competing Interest: None.

Submission 06-10-2016, Peer Review 01-11-2016,

Acceptance 07-11-2016, Published 14-11-2016.

Corresponding Author:

Dr. Deepa Longjam,

Department of Pathology,

J. N. Institute of Medical Sciences,

Imphal-795005,

Manipur.

E-mail: umeshtakhelmayum2014@gmail.com

DOI: $10.14260 /$ jemds/2016/1536

\section{(c) $(1)$}

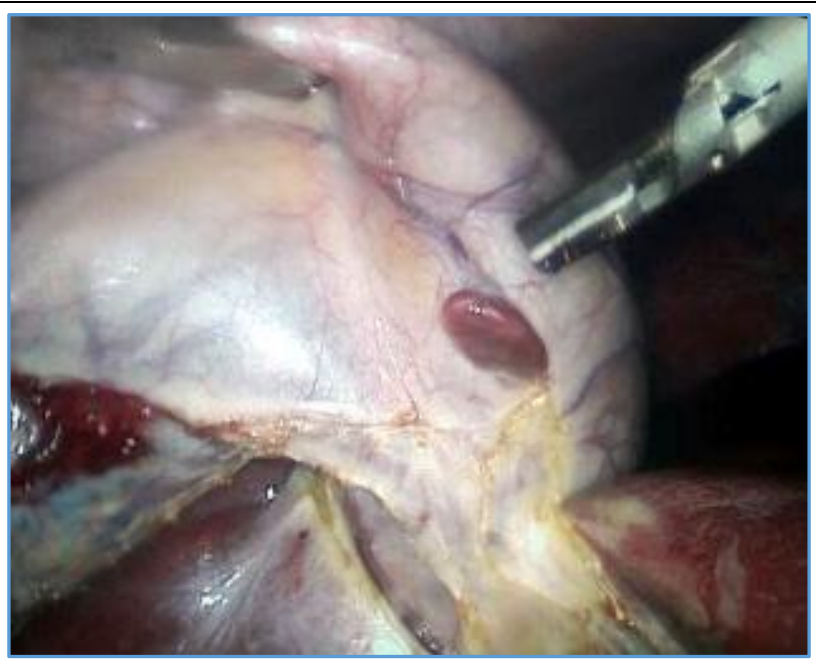

Figure 1

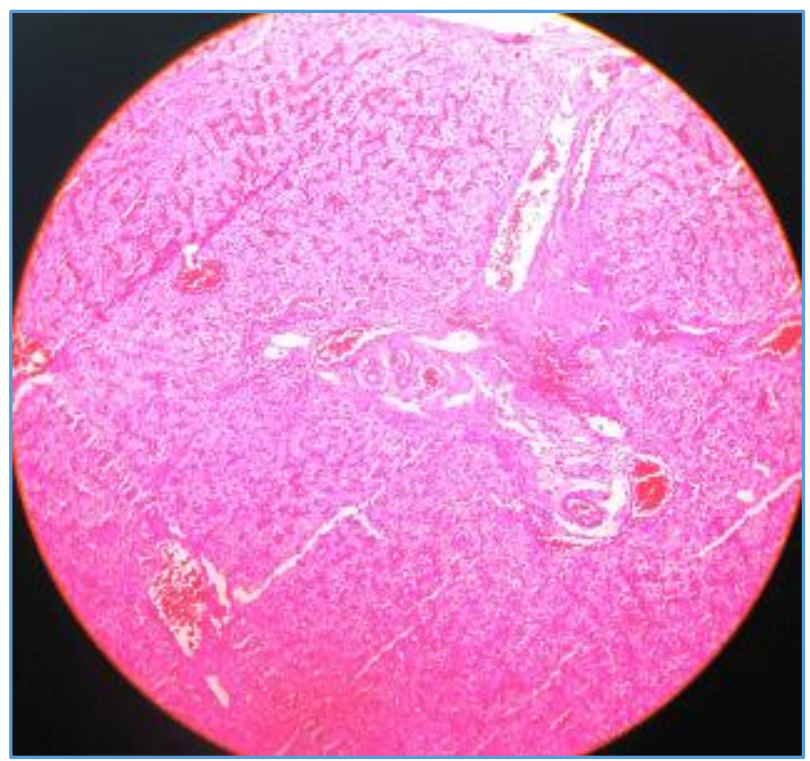

Figure 2

\section{DISCUSSION}

Ectopic liver is a rare condition incidentally identified during laparotomy or laparoscopy for other abdominal disorders. The incidence of the ectopic liver has been reported from 0.24 - 
$0.47 \%$ of the general population. It has been rarely described locating in the vicinity of liver such as on the gallbladder, hepatic ligaments, diaphragm, thoracic cavity, adrenal glands, pancreas, omentum, spleen, oesophagus and umbilical cord. ${ }^{2}$

However, the most common site of the ectopic liver is gall bladder. Hamdani $\mathrm{S}$ et $\mathrm{al}^{3}$ reported a $3 \mathrm{~cm}$ size of ectopic liver attached to gall bladder. Jonathan Lundy et $\mathrm{al}^{4}$ also reported a case of ectopic liver measuring $3.7 \mathrm{~cm}$ associated with fundus of the gall bladder. However, our finding is smaller $(<2 \mathrm{~cm})$ as compared to the above authors. Embryologically, the hepatobiliary system originates from the hepatic diverticulum in the direction of septum transversum during $4^{\text {th }}$ week of intrauterine life. Abnormal migration of some portion of hepatic diverticulum or the liver bud to other tissues is believed to be the cause of ectopic liver. It is usually attached to serosa of gall bladder, but it can also be in gall bladder lumen.2,5,6 Ectopic livers are divided into 4 categories namely a) Ectopic livers that are not connecting with the main liver and usually attached to the gall bladder or intra-abdominal ligaments, b) microscopic ectopic liver seen occasionally in the gall bladder, c) a large accessory liver attached to the main liver by stalk and d) a small accessory liver lobe attached to the main liver. ${ }^{7}$ Ectopic liver attached to gall bladder is usually asymptomatic and is found incidentally during laparoscopy as was this in our present case. It is also reported that ectopic liver is associated with other congenital anomalies such as biliary atresia, omphalocoele, bile duct cysts, caudate lobe agenesis, cardiac anomalies, etc. In our case, these anomalies were not seen. ${ }^{8}$ Awareness of such pathology is important in order to prevent mistaken diagnosis. Diagnoses by mean of imaging studies are rare and difficult. However, this can be one of the differential diagnoses when a radiologist identifies a soft tissue mass on gall bladder on imaging. In our case, the ultrasound examination before surgery revealed multiple stones in gall bladder with slight thickening of anterior wall of gall bladder. ${ }^{9}$ Histologically, pictures of ectopic liver are similar to liver proper with a central vein and portal tracts. There may be increase in number of blood vessels in the outer surface of gall bladder. There can also be fatty infiltration, cholestasis, hepatitis, haemosiderosis, cirrhosis or malignant degeneration to hepatocellular carcinoma (HCC) as in normal liver. Studies showed that ectopic liver increases the risk of developing HCC. Therefore, resection of the ectopic liver en bloc with the gall bladder is the standard treatment.2,5,10,11

\section{CONCLUSION}

Ectopic liver attached to gall bladder is a rare condition due to aberrant migration during the embryological development of liver. As there is increased risk of malignant degeneration to HCC, it should be diagnosed during laparoscopic procedures, removed and undergo histopathological examination.

\section{REFERENCES}

1. Koh CE, Hunt R. Ectopic liver encountered during laparoscopic cholecystectomy. Asian J Surg 2007;30(3):227-9.

2. Martinez CAR, de Resende HC, Rodrigues MR, et al. Gall bladder associated ectopic liver: a rare finding during a laparoscopic cholecystectomy. Int J Surg case Rep 2013;4(3):312-5.

3. Hamdani SD, Baron RL. Ectopic liver simulating a mass in the gall bladder wall: imaging findings. Am J Roentgenol 1994;162(3):647-8.

4. Lundy J, Johnson E, Edwards K, et al. Laparoscopic management of gall bladder associated ectopic liver. JSLS 2005;9(4):485-7.

5. Catani M, De Milito R, Romagnoli F, et al. Ectopic liver nodules: a rare finding during cholecystectomy. Giornale di Chirurgia 2011;32(5):255-8.

6. Cullen T. Accessory lobes of the liver. Arch Surg 1925;11:718-64.

7. Collan Y, Hakkiluoto A, Hastbacka J. Ectopic liver. Annales Chirurgiae Gynaecol 1978;67(1):27-9.

8. Griniatsos J, Riaz AA, Isla AM. Two cases of ectopic liver attached to the gall bladder wall. Journal of the International Hepato-pancreato-Biliary (Oxford) 2002;4(4):191-4.

9. Watanabe M, Matsura T, Takatori $Y$, et al. Five cases of ectopic liver and a case of accessory lobe of the liver. Endoscopy 1989;21(1):39-42.

10. Caygill CP, Gatenby PA. Ectopic liver and hepatocarcinogenesis. Eur J Gastroenterol Hepatol 2004;16(8):727-9.

11. Beltran MA, Barria C, Pujado B, et al. Hepatic heterotopic tissue on the gall bladder wall: an incidental finding with pathological potential. J Gastrointestin Liver Dis 2007;16(3):347-9. 